\title{
THE ROLE OF STATE PROGRAMS IN THE TRANSFORMATION OF THE AGRARIAN SECTOR IN AJARA AR
}

\author{
Nato Jabnidze ${ }^{1}$, Doctor of Business Management / Assistant Professor; Leila Tsetskhladze ${ }^{2}$, \\ Doctor of Business Management / Assistant Professor;Ia Meskhidze ${ }^{3}$, Doctor of Business \\ Management / Associate Professor \\ 1,2,3Batumi Shota Rustaveli State University
}

Report The Georgian economy has significant potential of growth and for enhancing competitiveness. Consequently, the state periodically encourages the creation of a favourable entrepreneurial and investment climate that is also systematically affected by active globalization processes on the world market. In order to alleviate these processes, the state is modernizing the economy and infrastructure sectors, part of which is the Autonomous Republic of Adjara and its agriculture. Promoting its development is important to the extent that addressing food security and sustainable development, increasing rural well-being, and reducing economic inequality between the village and the city depends on it.

The purpose of this paper is to study the role of state programs in the transformation of the agricultural sector, as we believe that minimizing state interference in the functioning of the agrarian sector cannot withstand global challenges, key financial, technical and technological support for the sector is relevant in the wake of negative external and internal economic conjuncture changes, which further aggravate food security and its financial sustainability. We believe that the development of effective mechanisms of optimizing and spending the integration of state and private resources needed for the socio-economic development of the country is still relevant today.

Keywords: Agriculture, Transformation, Government Programs, Agricultural Policy. JEL code: Q01, Q10

\section{Introduction}

The emergence of a market economy since the 1990s has put the need to transform the real economy sectors on the agenda. For the past twenty years, the agricultural sector has not played a key role in our country's development strategy, priority was given to areas requiring urgent reform, in particular effective governance and the promotion of free trade. However, implementation of the transformation process was also necessary in agriculture, which would take into account the development of business-oriented agriculture in addition to traditional household-based agriculture. Since 2010, this approach has been supported by the business sector, NGOs and donors.

Since the end of 2012, the Ministry of Agriculture has launched various programs in the agrarian sector and continues to this day. The Government of Georgia has taken significant and unprecedented steps for the country to develop agriculture and rural development, which has been reflected in large public investment in these areas. However, Georgia's rural development is still facing many challenges.

The decline of the mentioned field is indicated by the fact that, in the rural households' monetary income, only $21 \%$ of the income comes from the sale of agricultural products, while only $28 \%$ of the incomes from the agricultural sector of these households are commodities, the remaining $72 \%$ are natural incomes. In other words, under the conditions of a market economy, the level of per capita output produced by households is lower than that of a non-market planned economy. In the 1980 s, $45 \%$ of the total output of the private auxiliary population was cattle, $82 \%$ in $1989,22 \%$ in 1998, and now 18 \%. Therefore, we are dealing with the naturalization of agricultural production, which is an indicator of its low profitability. National Statistics Office of Georgia confirms this is in the share of agro-sector in total GDP. As shown in Figure 1, the share of primary agricultural production

${ }^{1}$ Nato Jabnidze e-mail: N.jabnidze@gmail.com

2Leila Tsetskhladze e-mail: Cecxladze.leila@bsu.edu.ge

${ }^{3}$ Ia Meskhidze e-mail: Meskhidze.ia@bsu.edu.ge 
in GDP does not reach even $10 \%$. And the share of the whole agrarian sector, which includes the processing of products, ranges from 13.6 to $16.4 \%$ over the years (2012-2018), which is extremely low.

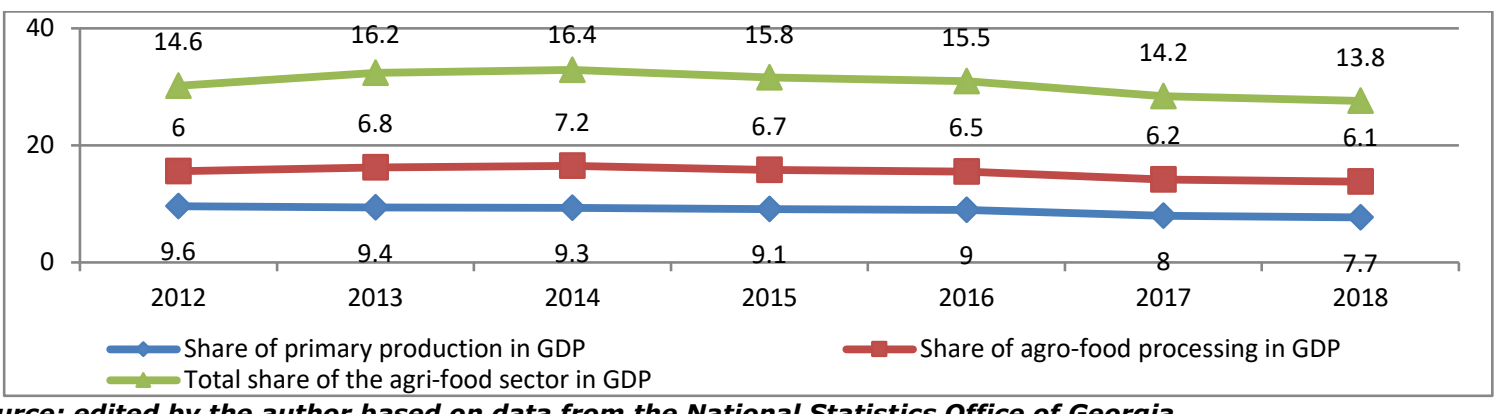

Source: edited by the author based on data from the National Statistics Office of Georgia.

\section{Fig. 1. Share of agribusiness sector in Georgian GDP (\%)}

It is important that agricultural policy is not only a strategy for the development of farms, but also an integral part of regional policy.

The purpose of this paper is to discuss the transformation of the agrarian sector in one of the largest regions of Georgia, the Autonomous Republic of Adjara, as well as identifying the problems that may arise during their implementation and selecting solutions.

The objectives of the study are to assess the general situation of the Georgian agricultural sector; Justify the necessity of the transformation process to increase the commercial load of products produced by family and farm businesses; To study the effectiveness of producing some traditional and new cultures and to develop recommendations for the problems we see in implementing state programs.

Theoretical-methodological bases of the research are methods of analysis, synthesis and comparison. The normative acts of economic and legal nature adopted by the government, scientific works of Georgian scientists and economists, statistical materials published by government and nongovernmental organizations on economics and agriculture, conclusions prepared by international organizations on agrarian policy implemented in the country and the reports prepared by the Ministry of Agriculture have been studied. Interviews were also conducted with various representatives of the agricultural sector, agrarian policy makers and other stakeholders, which enabled us to delve deeper into the issues under study and formulate recommendations.

\section{Research results and review}

There are different approaches to the development of the agricultural sector in Georgia today. Questions arise about the role of agriculture in Georgia's economy, development potential, opportunities to meet local demand for agricultural products, and the relative advantages. Most of the food consumed in Georgia today is actually imported. Consequently, the question arises as to what making agriculture a priority area will give us, what place does this sector occupy in Georgia's sectoral structure, whether it will be effective focusing on it and making additional investment, will we achieve economic growth, will poverty be reduced or not and etc.

Georgian scholars are of the same opinion that agriculture is an essential part of the country's economic development, that agriculture and food production cannot play a secondary role, as overcoming the poverty in Georgia cannot be achieved without the development of this sector. We believe that the decision to invest money in the development of the sector and to promote high quality products and export them is out of an alternative. We need to produce biologically pure and knowledgeable consumer-oriented products. 
Authorities have been confronted with the difficulties created by the inadequate attitude towards agriculture for decades. Consistent implementation of complex activities, support for farmers and agro-entrepreneurs are reflected in their awareness and consultation activities, direct implementation of programs and active involvement and financial and technical support by international donor organizations. As for foreign direct investment, agriculture is a field where the quality of foreign direct investment is very low. Currently, agriculture in Georgia is not an attractive field for foreign investment. The volume of FDI in Georgia is only $1 \%$ of total annual investments (2012-2018). However, the number of products produced by the sector as well as the added value shows an upward trend. In 2012, for example, agricultural sector output totalled GEL 3615.2 million, up $19 \%$ from 2010. The products released in 2018 are up $17.4 \%$ compared to the same period of 2017 and amounted to 4884.7 million. Gel. The value added in agriculture in 2014 exceeds that of 2013 by $40 \%$, while in 2018 the value added in 2017 and 2016 exceeds $8 \%$ and $23 \%$, respectively (National Statistics Office of Georgia, https://www.geostat.ge/ka/modules/categories/191/pirdapiriutskhouri-investitsiebi).

One of the key contributors to the development of agriculture is the Deep and Comprehensive Free Trade Area Agreement (DCFTA) with the EU, which provides for the bilateral and phasing-out of barriers to market access. Entering the EU market, in turn, requires the production of products that meet the standards set for the EU market, which are currently insufficiently secured. The EU's agricultural support strategy focuses on new aspects of production and safe food production. This means a return to traditional methods of production, where farmers receive added value. Concepts such as 'traditional food', 'organic food', 'local' or 'regional' are gaining new meaning. In developed countries, big attention is paid to agribusiness financing. The situation is similar in EU countries where food quality control and targeted assistance are brought to the level of state policy. We think that by enhancing the competitiveness of the Georgian product, we can gain a niche in the world market: Wine, nuts, tea, citrus, beekeeping products, fruits and more.

Proper agricultural policy implies a structural transformation that will not only enable the country to meet social goals, such as poverty alleviation in rural areas, but will also increase its commercial importance. We believe it is necessary to increase private equity investments and improve infrastructure together with the state. Approaches to regionalization and specialization of agriculture, sectoral integration and their development in regional-economic and technological problems require a new solution, with two key criteria in mind: Local environmental and economic conditions and internal and external marketing motivations, requirements, constraints, strategies that characterize and gradually characterize market relations. With the right organization of program-targeted budgeting, the quality of budget management is increased, substantially simplifying the implementation of public programs, monitoring process, and increasing the efficiency of public spending.

Since the emergence of agriculture as a priority sector, it has been necessary to ensure the involvement of private financial institutions, implementation of government programs, implementation of the insurance system, realization of projects of international organizations, private investment and other activities. The purpose of our study is to identify the role of government programs in the transformation process.

In Georgia, by the National Agency for Agricultural Projects Management are being prepared and implemented projects, such as: Preferential agro-credit, co-financing project for processing and 
saving enterprises, agro-support program, "Plant the future" Program, Tea Plantation Rehabilitation Program, Young Entrepreneur Program, agro insurance and more.

For example, the agro-production support program is being implemented under the AMMAR project. The program is funded by the International Fund for Agricultural Development (IFAD) and the Global Environment Facility (GEF). The project started in 2016 and consists of a component of primary production and a component of processing and savings enterprises. Total amount of investments in 2016-2018 amounted to GEL 21414 161, with 39.5\% share of state co-financing. One GEL grant invested by the state within the agri-production promotion program has attracted a GEL 1.53 investment. A total of 441 projects were funded (Ministry of Agriculture of Georgia).

The aim of the "Plant the future" project is to implement efficient cultivation of agricultural lands in Georgia by cultivating intensive perennial crops, introducing high-yielding varieties, replanting the varieties, replacing imported products with Georgian products, increasing exports, providing raw materials to processing plants, improving socio-economic situation of the rural population. Within the framework of this project, $1 \mathrm{GEL}$ investment by the state has attracted $0.81 \mathrm{GEL}$ private investment. From 31 December, 2015 to 31 December, 2018, 993 orchards of 6347347 ha are in total cultivation or are under cultivation.

Table 1

\section{Crops and investments that have been cultivated or are under cultivation in Georgia (2015-2018)}

\begin{tabular}{|l|c|c|c|c|}
\hline \multicolumn{1}{|c|}{ Crops } & Area (ha) & $\begin{array}{c}\text { Full investment } \\
\text { (GEL) }\end{array}$ & $\begin{array}{c}\text { State } \\
\text { co-financing } \\
\text { (GEL) }\end{array}$ & $\begin{array}{c}\text { Share of state } \\
\text { co-investments in total } \\
\text { investment (\%) }\end{array}$ \\
\hline Walnut & 2308 & 18677542 & 11055189 & 59 \\
\hline Almond & 893 & 6121690 & 3266410 & 53 \\
\hline Apple & 868 & 13697185 & 7022947 & 51 \\
\hline Nuts & 611 & 2266307 & 1184730 & 52 \\
\hline Blue cranberries & 286 & 7145078 & 4027380 & 56 \\
\hline Plum & 248 & 2199895 & 1161506 & 53 \\
\hline olive & 232 & 1826064 & 1145982 & 63 \\
\hline Raspberry & 145 & 2305042 & 1315492 & 57 \\
\hline other & 757 & 7685919 & 3995932 & 52 \\
\hline Total & $\mathbf{6 3 4 7}$ & $\mathbf{6 1 9 2 4 7 2 2}$ & $\mathbf{3 4 1 7 5 5 6 7}$ & $\mathbf{5 5}$ \\
\hline
\end{tabular}

Source: Ministry of Environment Protection and Agriculture of Georgia, Annual Report (2018).

Many projects approved by the Government of Georgia were implemented in 2013-2019, including in the Autonomous Republic of Adjara. Namely: promotion of small-scale farmers' spring works, preferential agro-credit project, co-financing of processing plants, agro-insurance program, industrial tangerine realization program, "Plant the future" program and more.

Since 2013, funding to support agro-sector development has increased substantially, and the programs under the Autonomous Republic's budget allocations have therefore consisted mainly of: 1) development and management of agricultural sector development policy; 2) facilitating the provision of mechanization facilities to farmers and agro-entrepreneurs; 3) supporting the development of the field of breeding; 4) supporting the development of the livestock sector; 5) agroservice development in the region 6) Laboratory research services. It should be noted that budgetary allocations of Ajara AR for each of these programs are increasing every year. In 2019, this indicator amounted to $9346354 \mathrm{GEL}$, which is 55\% more than in 2015 .

In Adjara, Autonomous Republic lowland protection and sustainable use of agricultural land is one of the priority directions. Improper agricultural practices, erosive landslides, soil contamination, soil 
degradation, climatic and anthropogenic factors are reducing land use, increasing food shortages and ensuring proper and rational management is a key issue in agricultural development.

It should also be noted that soil surveys and fertility monitoring are not systematically carried out and appropriate recommendations are not systematically developed. Fertilizer application is practically natural without any justification, causing a shortage of nutrients needed in almost all types of soil. Negative processes in the soil, such as moisture, secondary swamping, and leaching, have been strengthened, creating conditions for agricultural land to drop out of thousands of hectares and to move from high to low soils. $40 \%$ of agricultural land is characterized by high, $21 \%$ medium and 39\% low natural fertility (Meskhidze A., Abuladze J., 2016).

In Adjara, as one of the small territories of the region with unique natural-climatic conditions, it is important to develop the agrarian sector in terms of rational protection and use of natural resources. Land fund of the Autonomous Republic of Adjara is $290000 \mathrm{ha}$, which is $4.2 \%$ of the territory of Georgia. Of these, only 72862 ha are agricultural land, $52 \%$ of which is pasture land, $14 \%$ are arable land, $22 \%$ are perennial, $10 \%$ are mowing, and $2 \%$ are arable land (Meskhidze A., Abuladze J., 2016). The overwhelming majority of agricultural land registered to individuals in the Adjara region does not exceed $0.3-0.5$ ha on average, which indicates a high fragmentation rate. Under such conditions, the cost of agro-technical activities and logistics services increases, which increases the cost of production, hence the price.

The population of the Autonomous Republic of Adjara is 349 thousand people. The city has a population of 197.7 thousand and a population of 151.4 thousand. The percentage of rural population is $43.4 \%$ of the total population of the region. The overwhelming majority of them are involved in agricultural activities. Accordingly, for Adjara, agriculture is a prerequisite for the incomes and prosperity of half the population (Statistics, https://www.geostat.ge/regions/).

In the Autonomous Republic of Adjara, single-family and multi-year agricultural land can be differentiated by self-sufficient, potential commercialization and commercial opportunities. In the region, 85893 households are self-sufficient in terms of annual and perennial crop production in terms of potential commercialization opportunities and 23234 hectares of arable and perennial crops. The farms are grouped as follows.

1) 32272 households ( $37.6 \%$ ) have the opportunity to produce only products sufficient for their own needs, with a total of $3312(14.2 \%)$ ha. The overwhelming majority of such farms produces not one monoculture product for its subsequent sale (with rare exceptions), but mixed one-year agricultural crops, which are limited to producing a small number of different varieties.

2) 27408 family farms ( $31.9 \%$ ) have the opportunity to realize surplus products produced for their own use, with total use of 7345 ha $(31.6 \%)$.

3) 26213 Family farms (30.5\%) have the opportunity to develop farms for the purpose of sale of products, which use a total of 12587 (54.2\%) ha. (Putkaradze Z; Abuladze J; 2019).

4) As we can see, most of the family farms are not interested in producing products which later will be delivered to market. Therefore, the goal of the state should be to increase the motivation of family farms in this regard, requiring the transformation of the agrarian sector, one of the components of which may be the introduction of new crops that have the potential to be introduced in international markets due to high demand from consumers. This does not exclude the possibility of reviving traditional crops that require renewal, breeding, etc.

Governmental programs for rural development in the Autonomous Republic of Adjara aim to achieve goals such as promoting agriculture, agro-industry, regional development and stimulating 
exports. Another important consideration is to be taken into account: $54.4 \%$ of the territory of Georgia is located at 1000 meters above sea level. Opportunities for intensive agricultural production in most of these areas are limited. The development and traditions of environmentally friendly products in the economic uplift of Adjara Mountain and Highland Zone can make a significant contribution to the delivery of differentiated agrotourism products and the development of agrotourism.

Adjara's natural conditions are favourable for a wide variety of agricultural crops, including the main agricultural crops are tea, citrus fruits, fruits and vegetables. Citrus fruits are still in the first place among export crops. Subtropical technical crops were also planted in Adjara: Tung, bay leaf, bamboo, eucalyptus. Tobacco was the main technical culture in Adjara. Adjara was in second place in Georgia (after Abkhazia) in terms of quality tobacco.

Tea-growing is a traditional branch of agriculture in Georgia. This sector significantly contributed to the income of the population of Western Georgia and the country as a whole, as a large part of the volume of tea was exported. The average yield per hectare was 5.78 tonnes. Exports of Georgian tea peaked in 1984. In addition to the post-Soviet countries, 26,271 tonnes of tea were exported this year, including 5,719 tonnes in Mongolia, 5,250 tonnes in Poland, 5,500 tonnes in England and 6,000 tonnes in the Netherlands. By 1990, tea plantations occupied an area of 6,500 hectares in Adjara, most of which are now privatized in small plots (0.75-1.5 hectares on average), with mostly one-year crops cultivated, and by 2016, only 678 hectares of tea are cultivated in Adjara. Which makes up $6.7 \%$ of the total tea area in Georgia.

In our opinion, Adjara region tea can become competitive on the world market and occupy a niche market for biologically pure products. Therefore, the issue of planting new plantations of high productivity varieties and clones is on the agenda. Since 2016, the Tea Plantation Rehabilitation Project "Georgian Tea" has been under way, aiming to rehabilitate both the private sector and stateowned tea plantations, make effective use of the potential of tea, create modern tea processing plants and support the growth of local tea (including bio-tea) production. However, we believe that some of the constraints related to production, processing and marketing will need to be overcome in the development of the tea sector. 44 projects have already been funded in 2016-2018, 2403060 GEL has been invested for 959 ha rehabilitation area.

Tangerines have significant export potential, with average yields in Georgia being low at 3.6 tonnes per hectare and about 20 tonnes according to the Ministry of Agriculture of Georgia. Similar rates are much higher in other countries. For example, the average hectare yield in Turkey is 28.7 tonnes, in Peru 29.5Ctonnes. It is 30.9ctonnes in Korea and 36.4 tonnes in the US. The low average hectare yield of tangerines in Georgia is due to the large number of outdated and often depreciated crops. In order to solve this problem, the Ministry of Agriculture of Adjara has launched 28 different varieties of tangerine nursery in Chakvi cistern for demonstration. We think that tangerine is one of the most important crops of Georgian agribusiness, in order to increase export potential, it is necessary to increase competitiveness and improve the local product range. Promoting early maturity, frost-resistant, high-yielding varieties is of particular importance for promoting tangerine production in the country, enabling us to obtain quality and competitive fruit. The investment capital for cultivating 1 hectare of tangerine is GEL 13390, the return period is 7Cyears and IRR is $11 \mathrm{c} \%$ (Georgia Agri-Food Sector - For Your Investment. https://mepa.gov.ge/Ge/Page/investor). 
Production of tea and citrus in Georgia (thousand tones)

\begin{tabular}{|c|c|c|c|c|c|c|c|c|c|c|c|c|}
\hline & 2006 & \begin{tabular}{|l|} 
Share \\
in \%
\end{tabular} & \begin{tabular}{|c|}
201 \\
0
\end{tabular} & $\begin{array}{c}\text { Share } \\
\text { in \% }\end{array}$ & 2015 & $\begin{array}{l}\text { Share } \\
\text { in \% }\end{array}$ & 2016 & $\begin{array}{l}\text { Share } \\
\text { in \% }\end{array}$ & 2017 & \begin{tabular}{|c|} 
Share \\
in \%
\end{tabular} & 2018 & $\begin{array}{c}\text { Share } \\
\text { in \% }\end{array}$ \\
\hline Tea production Total & 6.6 & 100 & 3.5 & 100 & 2.1 & 100 & 3.0 & 100 & 2.3 & 100 & 1.7 & 100 \\
\hline Adjara AR & 0.0 & 0.0 & 1.0 & 28.5 & 0.9 & 42.8 & 0.8 & 27.0 & 0.4 & 17.0 & 0.6 & 35.0 \\
\hline Guria & 3.9 & 59.0 & 1.4 & 4.0 & 0.4 & 19.0 & 0.4 & 13.0 & 0.5 & 22.0 & 0.4 & 24.0 \\
\hline Imereti & 0.4 & 6.0 & 0.0 & 0.0 & 0.0 & 0.0 & 0.7 & 23.0 & 0.3 & 13.0 & 0.1 & 6.0 \\
\hline Samegrelo-Upper Svaneti & 2.3 & 34.8 & 1.1 & 31.4 & 0.8 & 38.0 & 1.1 & 37.0 & 1.1 & 48.0 & 0.6 & 35.0 \\
\hline Citrus Production Total & 52.2 & 100 & 52.1 & 100 & 77.6 & 100 & 65.5 & 100 & 58.2 & 100 & 66.3 & 100 \\
\hline In Adjara AR & 31.9 & 61.1 & 24.7 & 47.4 & 60.4 & 78.0 & 39.6 & 60.4 & 46.1 & 79.2 & 48.2 & 72.7 \\
\hline Guria & 11.3 & 21.6 & 24.2 & 46.4 & 13.3 & 17.0 & 22.4 & 34.1 & 10.9 & 18.7 & 13.3 & 20.0 \\
\hline Imereti & 0.0 & 0.0 & 0.1 & 0.2 & 0.4 & 0.5 & 0.4 & 0.6 & 0.2 & 0.3 & 0.4 & 0.6 \\
\hline Samegrelo-Upper Svaneti & 9.0 & 17.2 & 3.1 & 6.0 & 3.5 & 4.5 & 3.1 & 4.7 & 1.0 & 1.7 & 4.4 & 6.6 \\
\hline
\end{tabular}

Source: Compiled by the authors based on data from the National Statistics Agency of Georgia.

Given the current market demands and the comparative advantage of the Adjara region, blueberry is a promising field. Given that the market trend is towards sustainable and healthy foods, berries have the greatest market potential. Currently the supply of blueberry on the world market cannot meet demand. This berry needs about $30460 \mathrm{GEL}$ per hectare for cultivation. The return period is 5 years, with an IRR of $32 \%$. With proper planning and good management, blueberry plantation is profitable and can have a serious economic impact on small-scale farmers. (Berries on the European market USAID, REAP) Despite a number of problems related to logistics, scarcity of refrigerated farms, and lack of financial resources, at least 184.6 tonnes of blueberries were exported last season, almost double the previous year's figure. $90 \%$ (166.6 t) of export volume went to the Russian market.

To this day, one of the major impediments to agricultural development and competitiveness remains a difficult political situation (1992-1998). Implemented land reform that led to the fragmentation of small farms and the naturalization of production. One of the major challenges in the region remains the high level of fragmentation of agricultural land, which in turn has a significant negative impact on the efficiency and competitiveness of agricultural production. Insufficient attention is paid to unused or inefficient resources. By this we mean the improper or inappropriate use of techniques, seedlings, and other resources provided for free and / or by sharing. In Adjara, there is land use without registration, which impedes the development and consolidation of the land market, so the idea of promoting cooperatives was widely adopted.

It should be noted that the main problem of selling Georgian farmers' products is the fact that they enter the market separately, with inadequate knowledge and ineffective marketing measures, competing with each other and minimizing the cost of production. We believe that in the future it will be possible to unite them in order to deliver high quality products both domestically and abroad.

Due to the scarcity of technology, knowledge and financial resources, small farms cannot prevent major risks to agricultural products and ensure a stable supply of key markets. If small-scale farms make all the necessary investments to prevent these risks, then their activities will become economically disproportionate and unprofitable. Despite the hundreds of millions of GEL spent from the state budget, neither the spatial areas have increased nor the productivity of spatial areas increased to the required level, which indicates the inefficiency of budget spending.

The challenge remains to strengthen each value chain, train highly skilled staff, access to up-todate technologies, qualitatively and quantitatively increase local production, import substitution, export product growth, market diversification, bio-production, legislative regulation. 
We have not limited our views only and conducted in-depth interviews with representatives of the Ministry of Agriculture of Adjara, experts and beneficiaries benefiting from these programs in order to evaluate the state programs implemented in the agrarian sector of Adjara. The respondents were asked to rate the priorities of the programs, their strengths and weaknesses, the motivating factors for the programs, the existing gaps or expected difficulties that accompany the implementation of the program.

According to the direct implementers of the state programs, the measures are consistent and serve to increase the motivation of practitioners, resource provision, qualification, expansion of market opportunities based on sector development etc.

Through a survey of farmers, we found that the number and motivation for applying for the program were increasing, however; problems related to the lack of service centres for agro-technical repair were highlighted, difficulties in joining the program because of small land, lack of financial and other resources in many cases when requesting participation, the quality of nursery or seed material supplied and non-compliance with local conditions, etc. It is difficult for farmers to find export markets, and also in cases of falling prices due to abundant harvest may minimize profitability.

Experts in the field believe that programs implemented in the agrarian sector are inconsistent and not based on the needs and beliefs of farmers, farmer engagement rates are also considered to be unsatisfactory and indicate poor quality of nursery / seed material, the lack of consideration for climate conditions and traditions of farm development, the failure of land reform, the weakness of monitoring the spending of beneficiaries participating in the program.

\section{Conclusions and suggestions}

Thus, the study of the current state of the agro-food sector shows that the problem of providing the population with food products is worsening. Current trends in the modern global environment suggest that countries need both self-sufficiency and competitiveness to sustain, which is why we consider it necessary at the local level to implement the following:

- Proper agricultural policy implies a structural transformation that will not only enable the country to meet social goals, such as poverty alleviation in rural areas, but will also increase its commercial importance. We believe it is necessary to increase private equity investments and improve infrastructure together with the state. Approaches to regionalization and specialization of agriculture, sectoral integration and their development in regional-economic and technological problems require a new solution, with two key criteria in mind: local environmental and economic conditions and internal and external marketing motivations, requirements, constraints, strategies that characterize and gradually characterize market relations.

- Scientific research is needed to support the introduction of environmentally friendly, resourcesaving crop technologies and the production of competitive domestic crops. When implementing agro-programs it is necessary to take into account the knowledge and recommendations of experts in the field, which avoids unnecessary and inefficient use of resources.

- To enhance the competitiveness of agriculture, it is necessary to strengthen each value chain, introduce state-of-the-art technologies / innovations, expand the skills and capabilities of farmers. Technology-based industrial production is the only viable way to develop the agricultural sector. We also consider the importance of promoting and regulating bio-production.

- There has been a trend of increasing private investment in the agricultural sector lately, but access to financial resources is one of the major challenges for small and medium-sized 
entrepreneurs as well as for primary producers of agricultural products. There is a need for increased budgetary funds and active involvement of the banking sector.

- We consider it advisable to set up a system that would allow the state to lease land from unwilling landowners and transfer it to a farmer interested in producing agricultural produce. This, of course, requires strong political will, but it will be productive in terms of investment and increased production.

- Monitoring the spending of funds received from beneficiaries participating in public programs and monitoring the use of assets, which will facilitate the efficient spending and targeted use of budget funds.

\section{Bibliography}

1. Investigation of the Potential of Agricultural Products Produced in the Adjara Region in the Twentieth Century. (2017) Iberge Consulting LLC. Retrieved: http://adjara.gov.ge/uploads/Docs/b9dfb8d36c0f47359ee83072ef64.pdf

2. Berries on the European market. Export Guide. USAID,REAP

3. Georgian Agriculture., (2019). A statistic publication. Retrieved: https://www.geostat.ge/media/24487/soflis-meurneoba_2018.pdf

4. Georgian Agriculture., (2018). A statistic publication. Retrieved: https://www.geostat.ge/media/13795/2017-wlis-soflis-meurneoba.pdf

5. National Statistics Office of Georgia, Retrieved: https://www.geostat.ge/regions/.

6. National Statistics Office of Georgia, FDI in Georgia; Retrieved: https://www.geostat.ge/ka/modules/categories/191/pirdapiri-utskhouri-investitsiebi. Viewed: 15.02.2020

7. Statistical Yearbook (2019). Retrieved: https://www.geostat.ge/media/28915/Yearbook_2019.pdf

8. Georgian agri-food sector - for your investment. Retrieved: https://mepa.gov.ge/Ge/Page/investor. Viewed: 29.02.2020).

9. Meskhidze A. Abuladze J. (2016). "Agriculture in the Autonomous Republic of Adjara 2013-2016", Publishing Company "Geoprint", Tbilisi

10. Transformation of Georgia's agricultural sector: 20 Years of Independence, Interim Report, EI-LAT 2012 "European Initiative - Liberal Academy Tbilisi" 2015 Retrieved: http://adjara.gov.ge/uploads/Docs/fe90b91bc588426284035fb42e8d.pdf

11. Tea-growing in Georgia; Value chain analysis. (2015), Georgia, Tbilisi. TSU International School of Economics ISET;

12. Putkaradze Z., Abuladze J., 2019. Family Farms and Their Development Prospects in Adjara. J. Economics and Business, \# 4.

13. Cheng, K. (2015). Tea Production and Trade Worldwide: Current and Future Development. FAO Intergovernmental Group on Tea;

14. Ministry of Agriculture of Georgia. Retrieved: www.moa.gov.ge

15. Ministry of Agriculture, Agriculture Sector Strategy, 2020-2027.

16. Jabnidze N., Gurgenidze L., (2016). Support of Small Business and Tax Differentiation In Georgia. Innovative Economics And Management Volume 1 Ussue 1 ISSN:2449-2418 ISBN 9772449241009

17. Jabnidze N., (2016). Land Use Recommendations For Sustainable And Safe Development Of The Agricultural Sector. Periodical Scientific Journal "Khandzta" 13 (18). ISSN 15 12-3812 Kutaisi-Tbilisi, 139-149 pp.

18. Jabnidzde N., Meskhidze I., (2017). Role Of The State In The Process Of Creation And Functioning Of A Business Environment In Georgia. 18-19 MAY ISBN978-966-304-210-7 ST 200-204

19. Manvelidze I., Manvelidze R., (2019). Regional Peculiarities Of Public Political Communication According To The Example Of The Autonomous Republic Of Adjara. Conference Agenda SGEM. Conference Programme. Retrieved: https://sgemvienna.org/index.php/sgem-vienna-art-deadlines/conference-programme

20. Manvelidze R., Tsetskhladze L. (2018). Innovative Business: Development, Strategy, Prospects. IV International Scientific and Practical Conference "Strategic Imperatives of Modern Management". "". 19-20 april, Kyiv. Retrieved: http://ir.kneu.edu.ua/handle/2010/24199

21. Tsetskhladze L (2018). Trends of Impact of State Strategy On The Development of Entrepreneurship In Georgia. Monograph "Innovations in science: the challenges of our time" ISBN 978-1-77192-422-1. pp.390398.

22. Tsetskhladze M., (2016). Economic Potential of Georgia and Perspectives of Economic Integration with Europe" - Lupcon Center for Business Research - Finance and Economics Conference 2016 - in Frankfurt am Main, Germany August 1 until August 3.

23. Tsetskhladze M., (2017). Touristic Potential Of Adjara And Its Perspectives Of Sustainable Development. Scientific Letters Of Academic Society Of Michal Baludansky. ISSN 1338-9432. Volume 5, no. 5A/2017. Academic Society of Michal Baludansky, Kosicc, Slovakia,. Pp. 138-142; 